\title{
Desempenho de Ovinos em Terminação Alimentados com Dietas Contendo Diferentes Níveis de Dejetos de Suínos ${ }^{1}$
}

\author{
Cleber Medeiros Barreto ${ }^{2}$, Abelardo Ribeiro de Azevedo ${ }^{3}$, Ronaldo de Oliveira Sales ${ }^{4}$, \\ Francisco de Assis Vasconcelos Arruda ${ }^{5}$, Arnaud Azevêdo Alves ${ }^{6}$
}

\begin{abstract}
RESUMO - Objetivou-se, com esta pesquisa, avaliar o efeito de rações totais com diferentes níveis de dejetos de suínos no desempenho de ovinos confinados por 56 dias, com sete dias para adaptação e 49 para coleta de dados. Foram utilizados 32 ovinos machos não-castrados, Santa Inês, com média de sete meses de idade e peso vivo inicial de 25,2 $\pm 3,9 \mathrm{~kg}$, distribuídos em quatro grupos segundo o peso, seguindo-se o delineamento de blocos ao acaso, com quatro tratamentos (níveis de dejetos de suínos: T1 $=0 \%, \mathrm{~T} 2=4,2 \%, \mathrm{~T} 3=8,4 \%$ e T4=12,6\%). Não houve efeito dos tratamentos para consumo de MS $(89,44 \pm 1,01$ gMS/UTM e 3,83 $\pm 0,06 \%$ do PV), ganho de peso $(200,36 \pm 0,03 \mathrm{gPV} / \mathrm{animal} / \mathrm{dia})$ e conversão alimentar $(5,73 \pm 0,50 \mathrm{kgMS} / \mathrm{kgPV}$ ganho). Os resultados para consumo de PB foram de 0,71 ; 0,$72 ; 0,80$ e $0,78 \%$ do PV e 16,$81 ; 16,68 ; 18,53$ e 18,03 gPB/UTM, e para FDN, de 1,$61 ; 1,72 ; 1,91$ e 1,70\% PV e 35,82; 40,27 e 44,25, 38,81 gFDN/UTM, para as rações com $0 ; 4,2 ; 8,4$ e 12,6\% de dejetos de suínos, respectivamente. A inclusão de dejetos de suínos em até $12,6 \%$ das rações para ovinos terminados em confinamento resultou em desempenho satisfatório para ganho de peso diário e conversão alimentar. A a decisão pela utilização deste subproduto depende, portanto, do custo relativo dos demais ingredientes para formulação de rações a custo mínimo.
\end{abstract}

Palavras-chave: dejetos de suínos, fase de terminação, ovinos confinados, subprodutos

\section{Productive Performance of Confined Finishing Sheep Supplemented with Different Levels of Swine Waste}

\begin{abstract}
The objective of this research was to evaluate total rations with differents levels of swine waste on the productive performance of sheep, in a feedlot system during 56 days, where seven days of adaptation and 49 days for data collect. Were utilized 32 Santa Inês hair sheep, aged seven months aproximately and with average body weight of $25.2 \pm 3.9 \mathrm{~kg}$, distributed in four blocks as for body weight. A randomized complete block design, with four treatments (Swine waste levels: $\mathrm{T} 1=0 \%, \mathrm{~T} 2=4.2 \%, \mathrm{~T} 3=8.4 \%$ and $\mathrm{T} 4=12.6 \%)$ was followed. No effect of treatments to dry matter intake $\left(89.44 \pm 1.01 \mathrm{gDM} / \mathrm{kgW}^{0.75}\right.$ and $3.83 \pm 0.06 \%$ of the BW), average daily gain $(200.36 \pm 0.03 \mathrm{gBW} /$ animal/day $)$ and feed conversion $(5.73 \pm 0.50 \mathrm{kgDM} / \mathrm{kgBW}$ gain $)$ was observed. The results of treatments $\mathrm{T} 1, \mathrm{~T} 2, \mathrm{~T} 3$ and $\mathrm{T} 4$ for crude protein intake were $0.71,0.72,0.80$ and $0.78 \%$ of the $\mathrm{BW}$ and $16.81,16.68,18.53^{\mathrm{a}}$ and $18.03 \mathrm{gCP} / \mathrm{kgW}$. 0 , and for NDF intake 1.61, 1.72, 1.91 and $1.70 \%$ of the BW and $35.82,40.27,44.25$ and $38.81 \mathrm{gNDF} / \mathrm{kgW}^{0.75}$. The inclusion of swine waste until $12.6 \%$ on the diets for lamb males, in feedlot system had satisfactory result for average daily gain of body weight and feed conversion, and the decision of utilization of this by-product will be in function of the relative price of the others ingredients, focusing to reduce cost of the diet.
\end{abstract}

Key Words: by-products, feedlot sheep, swine waste, termination phase

\section{Introdução}

A terminação de cordeiros em confinamento apresenta uma série de benefícios, como menor mortalidade dos animais, em razão do maior controle sanitário e nutricional, o que resulta em abate precoce e carcaças com alta qualidade, refletindo em melhor preço ao consumidor e garantia ao produtor de retor- no mais rápido do capital investido. No entanto, as maiores desvantagens encontram-se nos altos custos de produção, principalmente com alimentação, que constitui fator determinante no aspecto financeiro (Oliveira et al., 2002).

A necessidade de intensificação da produção de ovinos requer a utilização de diversas fontes alimentares disponíveis, desde as convencionais até as

\footnotetext{
1 Parte da Dissertação apresentada pelo primeiro autor à UFC para obtenção do Grau de Mestre em Zootecnia.

2 Zootecnista, Mestre em Zootecnia (zoocleber@bol.com.br).

3 Pesquisador Doutor do PARTEC-NUTEC/UFC/CNPq (ara.nutritech@ig.com.br).

4 Professor Doutor do Departamento de Zootecnia do CCA/UFC (ronaldosales@secrel.com.br).

${ }^{5}$ Pesquisador Doutor da Embrapa Meio-Norte (arruda@cpamn.embrapa.br).

${ }^{6}$ Prof. Adjunto do DZO/CCA/UFPI, Doutor em Zootecnia (arnaud@ufpi.br).
} 
alternativas, que, na maioria dos casos, são responsáveis pela minimização dos custos de produção. Entre as fontes alternativas de alimentos, inclui-se dejetos de suínos, tanto pela disponibilidade, resultante da intensificação dos sistemas de produção (Anthony, 1970) e do número efetivo de suínos, de 36,5 milhões de animais (Roppa, 1999), quanto pela riqueza em nitrogênio desta fonte alimentar nas formas fresca ou tratada (Fonseca et al., 1997a). Além disso, o aproveitamento racional dos dejetos de suínos na alimentação animal contribui para minimizar seu impacto sobre o ambiente e favorece a produção de carne a baixo custo (Oliveira, 1993).

Segundo Oliveira (1993), os dejetos de suínos utilizados na alimentação animal podem ser caracterizados sob três formas: in natura, "DPS" - parte sólida, obtida pelo peneiramento do material contido na lâmina d'água das baias, seco ao sol e moído e "biju", dejeto retirado diretamente do piso das baias, seco ao sol e moído.

Fatores como alimentação, manejo, clima, água desperdiçada dos bebedouros e produção de urina podem influenciar a composição química dos dejetos de suínos (Oliveira, 1993). Ao avaliar a composição químico-bromatológica de dejetos de suínos na forma de "biju", provenientes de animais em crescimento e terminação, Kill et al. (1996), Oliveira et al. (1996) e Ferreira et al. (1997) obtiveram teores de MS de $85,14,85,30$ e $85,03 \%$; PB 25,35, 24,72 e 23,09\%; EB 4,13 e 4,27 Mcal/kg; FDN 22,74, 25,05 e 19,34\%; FDA $10,29,10,37$ e $7,85 \%$; EE 5,80 e 5,60\%; cinzas 18,24 e $17,30 \%$; Ca $2,78,2,88$ e $2,71 \%$; P $1,55,1,72$ e $1,26 \%$, respectivamente, com base na MS. Kill et al. (1996) atribuíram o alto teor de PB às diferenças nos teores protéicos das rações fornecidas aos animais e à presença de urina, que, segundo Arndt et al. (1977), contribui com pelo menos $50 \%$ do nitrogênio presente nos dejetos, tornando-se uma fonte potencial de nitrogênio não-protéico.

Apesar das vantagens apresentadas na literatura para o uso de dejetos suínos na alimentação de ruminantes, motivos de ordem superior levaram o Ministério da Agricultura, Pecuária e Abastecimento, por intermédio da Instrução Normativa MAPA número 15/2001, publicada no Diário Oficial da União, em 17 de julho de 2001, a proibir o uso de qualquer ingrediente ou matéria-prima que contenha vísceras de animais alimentados com proteína ou gordura de ruminantes (BRASIL, 2001). Esta pesquisa foi realizada em concomitância com a tramitação e aprova- ção da Instrução Normativa, de modo que os suínos produtores dos dejetos foram alimentados com fontes isentas de produtos de origem animal. No entanto, os resultados servem como referencial teórico para manejo e alimentação de ovinos confinados com idade avançada em sistema com alimentação alternativa.

Embora os sistemas tecnificados de produção intensiva de carne ovina sejam fundamentados na produção de ovinos precoces, no nordeste brasileiro ainda predomina a disponibilidade de animais para terminação em idade avançada, o que decorre do maior aproveitamento dos recursos naturais pelos ovinocultores fornecedores de animais para terminação. Assim, torna-se necessária a avaliação de mecanismos para convivência com esta realidade, objetivando não onerar os custos de produção, em virtude das limitações fisiológicas impostas pelos animais disponíveis.

Diante do exposto, com esta pesquisa, objetivouse avaliar o efeito da inclusão de diferentes proporções de dejetos desidratados de suínos "biju" em rações para ovinos em terminação.

\section{Material e Métodos}

O experimento foi desenvolvido no Setor de Digestibilidade do Departamento de Zootecnia (DZ) do Centro de Ciências Agrárias (CCA) da Universidade Federal do Ceará (UFC), em Fortaleza, CE, situado na zona litorânea, a $15,49 \mathrm{~m}$ de altitude, $3^{\circ} 46^{\prime} 02^{\prime \prime}$ de latitude sul e $38^{\circ} 33^{\prime} 35^{\prime \prime}$ de longitude oeste. Segundo a classificação de Köppen, o clima local é do tipo BS, estepe ou semi-árido, com duas estações (seca e chuvosa). A precipitação média anual é de $1.378 \mathrm{~mm}$ e a umidade relativa do ar média anual é de $77 \%$. As análises químico-bromatológicas foram efetuadas nos Laboratórios de Nutrição Animal do DZ/CCA/UFC e no Laboratório de Análises de Solos do Departamento de Solos/CCA/UFC. A digestibilidade in vitro foi determinada no Laboratório de Análises de Alimentos da EMBRAPA Caprinos, em Sobral, CE.

Foram utilizados 32 ovinos machos não-castrados da raça Santa Inês, com idade média de sete meses e peso vivo entre $21,4 \pm 3,3$ e 30,1 $\pm 1,6 \mathrm{~kg}$, distribuídos em 16 baias (dois animais/baia). As baias $\left(4 \mathrm{~m}^{2}\right)$ eram cobertas com piso concretado provido de cama de raspa de madeira e possuíam cochos para alimento e mistura mineral e bebedouro, segundo o delineamento experimental de blocos ao acaso, com quatro trata- 
mentos (níveis de dejeto de suínos), quatro repetições e dois animais por unidade experimental, considerando-se a baia como unidade experimental, para consumo e conversão alimentar, e os animais individualmente, para avaliação do ganho de peso, segundo o modelo matemático:

$$
\mathrm{Y}_{\mathrm{ijk}}=\mathrm{m}+\mathrm{T}_{\mathrm{i}}+\mathrm{B}_{\mathrm{j}}+\mathrm{e}_{\mathrm{ijk}}
$$

em que $\mathrm{Y}_{\mathrm{ijk}}=$ variável dependente a analisar; $\mathrm{m}=$ média geral; $\mathrm{T}_{\mathrm{i}}=$ efeito do tratamento $\mathrm{i}(\mathrm{i}=1,2$, $3,4) ; B_{j}=$ efeito do bloco $\mathrm{j}(\mathrm{j}=1,2,3,4) ; \mathrm{e}_{\mathrm{ijk}}=$ erro aleatório.

O confinamento teve duração de 56 dias, sendo sete para adaptação dos animais às instalações e às dietas, segundo metodologia proposta por Ruiz (1992). Ao início do período de adaptação, os animais foram identificados por brincos, pesados, vermifugados, receberam complexo vitamínico ADE via intramuscular e, após sorteio, foram distribuídos nos tratamentos. Neste período, foram feitos os ajustes de consumo, que consistiram das pesagens do alimento fornecido e das sobras, com acréscimo de $10 \%$ do total fornecido no dia anterior, segundo Lascano et al. (1992).

As rações experimentais foram constituídas por $40 \%$ de volumoso, feno de capim-tifton 85 (Cynodon spp.) triturado em picadeira com malha de $8 \mathrm{~mm} \mathrm{e}$ $60 \%$ de ração concentrada contendo diferentes níveis de dejetos de suínos. As rações foram calculadas segundo recomendações do NRC (1985), constituindo os tratamentos experimentais, conforme a Tabela 1.

O dejeto de suínos na forma de "biju", caracterizado por Oliveira (1993), continha, além de

Tabela 1 - Composições centesimal e químico-bromatológica e digestibilidade in vitro da matéria seca (DIVMS) das rações experimentais (\% na MS)

Table 1 - Percentage composition and bromatological and in vitro digestibility of dry matter (IVDMS) of the experimental diets

\begin{tabular}{|c|c|c|c|c|}
\hline \multirow[t]{2}{*}{$\begin{array}{l}\text { Parâmetros } \\
\text { Parameters }\end{array}$} & \multicolumn{4}{|c|}{$\begin{array}{c}\text { Rações experimentais (Tratamentos) } \\
\text { Experimental diets (Treatments) }\end{array}$} \\
\hline & $\begin{array}{c}\mathrm{T}_{1} \text { - Controle } \\
T_{1} \text { - Control }\end{array}$ & $\begin{array}{l}\mathrm{T}_{2}-4,2 \% \\
T_{2}-4.2 \%\end{array}$ & $\begin{array}{l}\mathrm{T}_{3}-8,4 \% \\
T_{3}-8.4 \%\end{array}$ & $\begin{array}{l}\mathrm{T}_{4}-12,6 \% \\
T_{4}-12.6 \% \\
\end{array}$ \\
\hline \multicolumn{5}{|l|}{ Ingredientes (\%) } \\
\hline $\begin{array}{l}\text { Feno de capim-tifton } 85 \\
\text { Cynodon spp hay }\end{array}$ & 40,000 & 40,000 & 40,000 & 40,000 \\
\hline \multicolumn{4}{|l|}{ Corn grain } & 25,903 \\
\hline \multicolumn{4}{|l|}{ Soybean meal } & 18,045 \\
\hline & \multicolumn{2}{|c|}{ Wheat meal } & 9,668 & 3,452 \\
\hline \multicolumn{5}{|c|}{ Swine waste } \\
\hline \multicolumn{5}{|c|}{ Composição químico-bromatológica } \\
\hline $\begin{array}{l}\text { Matéria seca }(\%) \\
\text { Dry matter (\%) } \\
\% \text { da MS }\end{array}$ & 88,80 & 89,49 & 87,80 & 89,31 \\
\hline$\%$ of $D M$ & 16,76 & 16,99 & 18,38 & 18,07 \\
\hline \multicolumn{5}{|l|}{ Crude protein } \\
\hline $\mathrm{FDN}(N D F)$ & 47,30 & 49,77 & 52,61 & 47,30 \\
\hline $\mathrm{FDA}(A D F)$ & 23,75 & 24,60 & 24,14 & 24,88 \\
\hline $\mathrm{MM}(A s h)$ & 3,79 & 5,98 & 7,00 & 8,28 \\
\hline $\mathrm{NDT}^{*} T D N^{*}$ & 68,90 & 67,92 & 67,00 & 67,00 \\
\hline $\mathrm{Ca}$ & 0,53 & 0,76 & 0,95 & 1,25 \\
\hline $\mathrm{P}$ & 0,46 & 0,60 & 0,75 & 0,85 \\
\hline DIVMS (IVDMS) & 60,57 & 58,50 & 53,84 & 54,97 \\
\hline
\end{tabular}

*Estimado a partir de dados de Rodrigues et al. (1996b), para dejetos de suínos "biju", Ribeiro et al. (2001), para feno de capim-tifton 85, e de Campos (1995), para milho em grão, farelo de soja e farelo de trigo.

* Estimated with dates of Rodrigues et al. (1996b), to swine wastes "biju", Ribeiro et al. (2001), to Cynodon spp hay, and of Campos (1995), to corn grain, soybean meal and wheat meal.

R. Bras. Zootec., v.33, n.6, p.1858-1865, 2004 (Supl. 1) 
dejetos, restos de ração e pêlos, e foi obtido no Setor de Suinocultura do DZ/CCA/UFC, de matrizes adultas alimentadas com ração composta, com base na matéria natural, por $81,7 \%$ de milho em grão, $14,3 \%$ de farelo de soja, $0,5 \%$ de sal comum e 3,5\% de um premix vitamínico mineral com os seguintes níveis de garantia/kg do produto: Vit. A 200.000 UI; Vit. $\mathrm{D}_{3}$ 40.000 UI; Vit. E $350 \mathrm{mg}$; Vit. $\mathrm{K}_{3} 50,44 \mathrm{mg}$; Vit. B $25,48 \mathrm{mg}$; Vit. $\mathrm{B}_{2} 105,60 \mathrm{mg}$; Vit. $\mathrm{B}_{6} 25,48 \mathrm{mg}$; Vit. $B_{12} 400 \mathrm{mg}$; ácido nicotínico $607,60 \mathrm{mg}$, pantotenato de cálcio $400 \mathrm{mg}$; biotina $1,00 \mathrm{mg}$; ácido fólico 5,82 mg; cloreto de colina $4.000 \mathrm{mg}$; Ca $245 \mathrm{~g}$; P 92,50 g; NaCl $125 \mathrm{~g}$; Iodo 12,92 mg; Cu $230 \mathrm{mg}$; Co $10 \mathrm{mg}$; Fe $2.500 \mathrm{mg}$; Mn $1.000 \mathrm{mg}$; Zn $2.500 \mathrm{mg}$; Se 9,00 mg; F $925 \mathrm{mg}$; antioxidante BHT 0,02\%; veículo q.s.p. $1.000 \mathrm{~g}$.

Durante o período experimental, as rações foram fornecidas à vontade, em duas refeições, às $8 \mathrm{e}$ $16 \mathrm{~h}$. Para o preparo da ração total de cada tratamento, a mistura concentrada e o volumoso foram pesados separadamente e, em seguida, misturados. Além das rações experimentais, os animais tiveram livre acesso à água e ao suplemento vitamínicomineral da marca comercial FRI-PHÓS Ovicapri ${ }^{\circledR}$, com a composição e níveis de garantia apresentados pelo fabricante.

Para as análises químico-bromatológicas, foram coletadas amostras dos ingredientes (dejeto de suínos, concentrados e volumoso) que representaram os alimentos e rações fornecidas e das sobras coletadas diariamente, obtendo-se amostras compostas semanais, que foram armazenadas em freezer à temperatura de $-5^{\circ} \mathrm{C}$ a $-10^{\circ} \mathrm{C}$.

Foram avaliados os consumos médios $(\% \mathrm{PV}$ e g/UTM/animal/dia) de MS, de PB e de FDN das rações experimentais. A estimativa do consumo de nutrientes digestíveis totais (NDT) seguiu a equação proposta por Fonseca et al. (1997b) $\hat{Y}=-0,23+1,02$ MSD, $R^{2}=0,992$, em que $\hat{\mathrm{Y}}=$ consumo de NDT, em $\mathrm{kg} / \mathrm{dia}$, e MSD = consumo de matéria seca digestível, em $\mathrm{kg} /$ dia.

As pesagens dos animais foram realizadas a cada sete dias, sempre no mesmo horário, antes da primeira refeição, após jejum de 16 horas. Ao completar 49 dias do período experimental, os animais foram pesados para obtenção do peso vivo final, do ganho de peso diário e da conversão alimentar.

Para análise das amostras de rações totais, sobras alimentares, dejeto de suínos e feno de capimtifton 85 , procedeu-se a pré-secagem a $55^{\circ} \mathrm{C}$ em estufa de circulação forçada de ar, por 24 horas. Em seguida, as amostras foram trituradas em moinho do tipo Willey com peneira de malha $0,5 \mathrm{~mm}$ e armazenadas em vidros âmbar hermeticamente fechados e identificados.

As análises químico-bromatológicas da MS, PB, EE, MM, Ca e P seguiram a metodologia descrita pela Association of Official Analytical Chemists - AOAC (1990) e os teores de FDN e FDA foram obtidos por intermédio do método de Van Soest, descrito por Silva \& Queiroz (2002).

A digestibilidade in vitro da MS, do feno de capim-tifton 85 , do dejeto de suínos e das rações totais seguiu a técnica de duas etapas, proposta por Tilley \& Terry (1963), descrita por Silva \& Queiroz (2002). Após 48 horas de fermentação no líquido de rúmen, o substrato foi submetido à fermentação ácida com pepsina por mais 48 horas. Os dados de digestibilidade foram obtidos pela diferença de peso encontrada para MS entre as pesagens efetuadas antes e após a incubação.

Os resultados obtidos foram submetidos à análise da variância pelo teste $t$ de Student e à análise de regressão, utilizando-se o procedimento PROC REG do logiciário estatístico SAS (2000).

\section{Resultados e Discussão}

Na Tabela 1, são apresentados os resultados de composição químico-bromatológica e digestibilidade in vitro da matéria seca das rações experimentais. A composição químico-bromatológica do dejeto de suínos na forma de "biju" utilizado na formulação das rações experimentais revelou teores de MS 90,95\% e, com base na MS, PB 19,40\%, EE 3,29\%, FDN $46,80 \%$, FDA $23,45 \%$, cinza $30,89 \%$, Ca $4,68 \%$ e P $3,57 \%$ e digestibilidade in vitro da MS $41,77 \%$. O resultado encontrado para MS foi superior ao obtido por Pérez et al. (2000) e Rodrigues et al. (1996b), ao avaliarem dejeto de suínos na forma de "biju", com $83,7 \%$ e $83,68 \%$ de MS, respectivamente. O valor obtido para PB foi inferior aos relatados por Kill et al. (1998), de 24,72\% na forma de "biju", e por Fonseca et al. (1997a), que obteve para dejeto de suínos in natura $23,4 \%$ de PB na MS. Entretanto, foi superior ao valor de $11,74 \%$ de $\mathrm{PB}$, verificado por Castro (1999), em dejeto de suínos na forma de "DPS".

Os resultados para FDN e FDA do dejeto de suínos são superiores aos obtidos por Pérez et al. (2000) de 22,5 e $10,4 \%$, respectivamente, e 
aproximam-se do obtido por Fonseca et al. (1997a), de 43,8\% de FDN, ambos com base na MS. Os teores de EE na MS, relatados por Fonseca et al. (1997a), Rodrigues et al. (1996b) e Kill et al. (1998), de 5,8\%, $7,95 \%$ e $5,60 \%$, respectivamente, superam o encontrado nesta pesquisa. O resultado para cinza obtido neste trabalho foi muito superior aos obtidos por Pérez et al. (2000), de 14,7\%, e por Kill et al. (1998) de $17,30 \%$, sendo semelhante ao obtido por Castro (1999), de 31,25\%. Os dados para Ca e P superaram os obtidos por Fonseca et al. (1997a), para dejeto de suínos, de 3,8 e 2,2\%, respectivamente.

As diferenças dos teores de MS, PB, FDN, FDA, EE e minerais, em relação aos referenciados na literatura, podem ser atribuídas ao processo de secagem do dejeto de suínos, fator determinante de variação nos teores de MS e PB. Destacam-se, ainda, variações na composição das rações dos animais produtores dos dejetos quanto aos teores de proteína, fibra, extrato etéreo e de minerais, como também ao efeito da forma de coleta sobre o conteúdo de nitrogênio e de minerais.

A composição químico-bromatológica do feno de capim-tifton 85 utilizado como volumoso nas rações experimentais revelou teores de MS 90,16\%, e, com base na MS, de PB 4,70\%, FDN 87,83\%, FDA
$50,10 \%$, cinza $6,18 \%$, Ca $0,61 \%$ e $\mathrm{P} 0,17 \%$, e digestibilidade in vitro da matéria seca de 19,95\%.

Embora tenham sido estabelecidos níveis protéicos das rações experimentais de $16,7 \%$, com base no NRC (1985), as variações nos teores de proteína dos ingredientes em relação aos valores de referência estabelecidos em tabelas de composição bromatológica levaram às diferenças observadas na Tabela 1 , quando das análises químico-bromatológicas. No entanto, a variação entre o valor previsto e o maior teor obtido, no tratamento 3 , foi de 1,68 pontos percentuais.

A inclusão de dejeto de suínos não proporcionou diferença significativa $(\mathrm{P}>0,05)$ no consumo de MS das rações experimentais (Tabela 2 ).

Os resultados médios para consumo, de $89,44 \pm 1,01$ $\mathrm{gMS} / \mathrm{UTM} /$ dia e 3,83 $\pm 0,06 \%$ do PV, estão abaixo dos valores preconizados pelo NRC (1985), de 5,0\% e $4,3 \%$ do PV para ovinos com 20 e $30 \mathrm{~kg}$, respectivamente todavia superam os resultados obtidos por Castro (1999), de 77,35 $\pm 4,88 \mathrm{gMS} / \mathrm{UTM} / \mathrm{dia}$; por Pérez et al. (2000), de 71,7 gMS/UTM/dia, com ração contendo $60 \%$ de feno de coastcross (Cynodon spp.) e $40 \%$ de dejeto de suínos na forma de "biju"; por Martins (1997), de 53,5 e 42,4 gMS/UTM/dia, com rações contendo dejeto de suínos na forma de "biju" e feno de coastcross, nas proporções de 60:40

Tabela 2 - Consumos de matéria seca (CMS), de proteína bruta (CPB) e de fibra em detergente neutro (CFDN) por ovinos alimentados com rações contendo diferentes níveis de dejeto de suínos

Table 2 - Intakes of dry matter (DMI), crude protein (CPI) and neutral detergent fiber (NDFI) to sheep fed diets with different levels of swine wastes

\begin{tabular}{|c|c|c|c|c|c|}
\hline \multirow[t]{2}{*}{$\begin{array}{l}\text { Parâmetros } \\
\text { Parameters }\end{array}$} & \multicolumn{4}{|c|}{$\begin{array}{l}\text { Rações experimentais (Tratamentos) } \\
\text { Experimental diets (Treatments) }\end{array}$} & \multirow[b]{2}{*}{$\mathrm{CV}(\%)$} \\
\hline & $\begin{array}{c}\mathrm{T}_{1}-\text { Controle } \\
T_{1}-\text { Control }\end{array}$ & $\begin{array}{l}\mathrm{T}_{2}-4,2 \% \\
T_{2}-4.2 \%\end{array}$ & $\begin{array}{l}\mathrm{T}_{3}-8,4 \% \\
T_{3}-8.4 \%\end{array}$ & $\begin{array}{l}\mathrm{T}_{4}-12,6 \% \\
T_{4}-12.6 \%\end{array}$ & \\
\hline \multicolumn{6}{|l|}{ Consumo de MS (DM intake) } \\
\hline$\% \mathrm{PV}(\% B W)$ & $3,77^{\mathrm{a} *}$ & $3,77^{\mathrm{a}}$ & $3,90^{\mathrm{a}}$ & $3,88^{\mathrm{a}}$ & 6,6 \\
\hline $\mathrm{g} / \mathrm{UTMg}\left(\mathrm{kg} W^{0.75}\right)$ & $89,01^{\mathrm{a}}$ & $88,12^{\mathrm{a}}$ & $90,58^{\mathrm{a}}$ & $90,07^{\mathrm{a}}$ & 6,9 \\
\hline Consumo de PB (CP intake) & & & & & \\
\hline$\% \mathrm{PV}(\% B W)$ & $0,71^{\mathrm{b}}$ & $0,72^{\mathrm{ab}}$ & $0,80^{\mathrm{a}}$ & $0,78^{\mathrm{ab}}$ & 6,8 \\
\hline $\mathrm{g} / \mathrm{UTMg}\left(\mathrm{kg} W^{0.75}\right)$ & $16,81^{\mathrm{ab}}$ & $16,68^{b}$ & $18,53^{\mathrm{a}}$ & $18,03^{\mathrm{ab}}$ & 6,4 \\
\hline Consumo de FDN (NDF intake) & & & & & \\
\hline$\% \mathrm{PV}(\% B W$ & $1,61^{\mathrm{b}}$ & $1,72^{\mathrm{b}}$ & $1,91^{\mathrm{a}}$ & $1,70^{\mathrm{b}}$ & 6,4 \\
\hline $\mathrm{g} / \mathrm{UTM}\left(\mathrm{kg} W^{0.75}\right)$ & $35,82^{\mathrm{b}}$ & $40,27^{\mathrm{ab}}$ & $44,25^{\mathrm{a}}$ & $38,81^{\mathrm{ab}}$ & 8,6 \\
\hline $\begin{array}{l}\text { Ganho de peso (Weight gain) } \\
\text { g/animal/dia (g/animal/day) }\end{array}$ & $201,57^{a *}$ & $199,37^{\mathrm{a}}$ & $192,25^{\mathrm{a}}$ & $208,25^{\mathrm{a}}$ & 17,22 \\
\hline $\begin{array}{l}\text { Conversão alimentar (Feed:gain ratio) } \\
\text { gMS/g peso ganho (gDM/g weight gain) }\end{array}$ & $5,86^{\mathrm{a}}$ & $5,59^{\mathrm{a}}$ & $5,88^{\mathrm{a}}$ & $5,61^{\mathrm{a}}$ & 8,80 \\
\hline
\end{tabular}

*Médias seguidas por letras diferentes nas linhas diferem estatisticamente pelo teste $t$ de student $(P<0,05)$.

${ }^{*}$ Averages followed by differents letters differ in the lines by $t$ student test $(P<.05)$.

R. Bras. Zootec., v.33, n.6, p.1858-1865, 2004 (Supl. 1) 
e 40:60 feno: "biju", respectivamente; e por Tinnimit et al. (1972), de 2,8\% do PV.

Com base na equação proposta por Fonseca et al. (1997b), foram obtidos consumos de nutrientes digestíveis totais (NDT) de 499, 440, 390 e $405 \mathrm{gNDT} /$ animal/dia a partir dos resultados para consumo de matéria seca digestível (MSD) para as rações experimentais $\mathrm{T}_{1}, \mathrm{~T}_{2}, \mathrm{~T}_{3} \mathrm{e} \mathrm{T}_{4}$, de 715, 657, 608 e $623 \mathrm{gMSD} /$ animal/dia, respectivamente.

Os resultados para consumo de energia (NDT) mostraram-se inferiores aos recomendados pelo NRC (1985), de 800 e 1000 gNDT/dia, para ovinos com 20 e $30 \mathrm{~kg}$ de peso vivo, respectivamente. No entanto, estas recomendações visam atender às exigências de animais recém-desmamados e com potencial de crescimento moderado, não se aplicando aos animais utilizados neste experimento, que apresentavam cerca de sete meses de idade e peso vivo entre $21,4 \pm 3,3$ a $30,1 \pm 1,6 \mathrm{~kg}$. Além disso, merece destaque o baixo valor nutritivo do volumoso utilizado, com reflexo na baixa digestibilidade in vitro das rações experimentais (Tabela 1).

Verificou-se diferença significativa $(\mathrm{P}<0,05)$ entre tratamentos para consumo de $\mathrm{PB}$, com base na $\%$ do PV, com superioridade do tratamento com nível de inclusão do dejeto de suínos na proporção de $8,4 \%$ em relação ao tratamento com nível $0 \%$, sendo os tratamentos com níveis de 4,2 e $12,6 \%$ não diferentes significativamente $(\mathrm{P}>0,05)$ dos demais, enquanto, com base no tamanho metabólico, a diferença entre 8,4 e $0 \%$ de dejeto de suínos não se configurou (Tabela 2). Estes resultados apresentam certa proporcionalidade com os níveis protéicos das rações experimentais (Tabela 1). Embora o estabelecimento das rações experimentais como isoprotéicas tenha sido objetivado, quando da análise químico-bromatológica, verificou-se maiores teores de PB nos tratamentos com níveis de $8,4 \%$ e $12,6 \%$ em relação aos tratamentos 0 e 4,2\%, o que pode ter contribuído para as diferenças de consumo obtidas para este constituinte.

Os resultados de consumo de $\mathrm{PB}$ para os diferentes tratamentos (Tabela 2) foram superiores

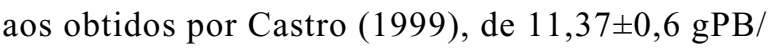
$\mathrm{UTM} /$ dia, em experimento com rações contendo níveis de inclusão do dejeto de suínos peneirado e seco ao sol (DPS) na proporção de até $45 \%$ da ração, e aos obtidos por Pérez et al. (2000), de 11,1 e 12,2 $\mathrm{gPB} / \mathrm{UTM} /$ dia, ao utilizarem dietas compostas por feno e dejeto de suínos nas proporções 60:40 e 40:60, respectivamente.
O consumo de FDN em relação ao peso vivo e tamanho metabólico apresentou diferença significativa $(\mathrm{P}<0,05)$ entre tratamentos. Verificou-se superioridade do tratamento com nível de $8,4 \%$ de dejeto de suínos em relação aos demais, o que reflete o maior teor de FDN obtido neste tratamento (Tabela 2). Entretanto, com base no tamanho metabólico, verificou-se diferença apenas entre os níveis 0 e $8,4 \%$, com maior consumo de FDN para o nível de $8,4 \%$, não diferente significativamente $(\mathrm{P}>0,05)$ dos níveis 4,2 e $12,6 \%$, respectivamente.

Os resultados obtidos para consumo de FDN, com base no tamanho metabólico, quando comparados aos encontrados por Pérez et al. (2000), que testaram o efeito de dois níveis de inclusão de dejeto de suínos na forma de "biju" em rações compostas por $60 \%$ feno: $40 \%$ "biju" e por 40\% feno:60\% "biju", indicam que a primeira ração apresentou resultado próximo $(40,9 \mathrm{~g} /$ UTM/dia) aos deste trabalho, enquanto a segunda ração (40:60) apresentou resultado inferior (30,5 g/ UTM/dia), fato observado de forma plausível quando da diminuição da proporção volumoso:concentrado. Isto comprova forte relação entre o consumo de FDN e aspectos quantitativos do volumoso (proporção e valor nutritivo), pois o feno de capim-tifton 85 , utilizado nas rações experimentais, apresentava elevado teor de FDN (87,83\% na MS), proporcionando consumo relativamente alto de FDN em todos os tratamentos, mesmo com a proporção das rações totais de 40 e $60 \%$, para volumoso e concentrado, respectivamente.

Em todos os tratamentos, os consumos de FDN em relação ao peso vivo e tamanho metabólico foram menores que os obtidos por Castro (1999), de 2,8\% do $\mathrm{PV}$ e 47,98 gFDN/UTM/dia, respectivamente, com a inclusão de dejeto de suínos na forma de "DPS" na proporção de $10 \%$ da ração total, constituída por $65 \%$ de volumoso à base de capim-elefante (Pennisetum purpureum Schum.) e feno de leucena (Leucaena leucocephala (Lam.) De Wit.) e 45\% de concentrado, apresentando 71,55\% de FDN na MS.

Não houve diferença significativa $(\mathrm{P}>0,05)$ entre tratamentos para ganho de peso diário e conversão alimentar (Tabela 2).

Os resultados para ganho de peso diário $(200,36 \pm 0,03 \mathrm{~g})$, foram superiores aos obtidos por Castro (1999), que variaram de 19,20 a 57,37 g/dia. A grande diferença observada entre os experimentos deve-se, possivelmente aos níveis de inclusão testados por Castro (1999), de até 40\% de dejeto de suínos na forma de "DPS" na ração total, ao passo que, 
neste trabalho, foram incluídos até $12,6 \%$ da ração total, visando atender às recomendações do NRC (1985) e mantendo as rações isoenergéticas.

Outro fator que pode ter contribuído para maiores ganhos de peso diários foram as características dos animais utilizados, com sete meses de idade, padrão racial Santa Inês e machos não-castrados, enquanto Castro (1999) trabalhou com animais em idade mais avançada (12 meses), sem raça definida e de ambos os sexos, sendo os machos castrados, o que está de acordo com o preconizado por Carvalho et al. (1999), que, para ovinos em idade mais avançada, a maior ação do hormônio masculino (testosterona) pode resultar em maior desempenho dos machos nãocastrados (Carvalho et al., 1999).

Os resultados para ganho de peso diário também superaram os obtidos por Rodrigues et al. (1996a), que testaram a inclusão de $30 \%$ de dejeto de suínos no concentrado em uma ração composta por $20 \%$ de feno de aveia e $80 \%$ de concentrado para ovinos machos das raças Bergamácia e Santa Inês, com efeito destes ingredientes sobre o ganho de peso, com $199 \mathrm{~g} / \mathrm{animal} /$ dia na ração testemunha e, em média, $160 \mathrm{~g} /$ animal/dia para as rações com "DPS" e "biju", o que pode ter decorrido da maior inclusão de "biju", $24,0 \%$ da MS total da ração, em relação ao máximo de $12,6 \%$ da MS total da ração utilizada neste trabalho.

Os resultados para conversão alimentar de $5,73 \pm 0,50 \mathrm{gMS} / \mathrm{g}$ de peso ganho (Tabela 2) apresentaram respostas bastante inferiores às obtidas por Carvalho et al. (1999), de 3,76 a 4,55, ao compararem machos não-castrados, machos castrados e fêmeas, com idade inicial de 50 dias, alimentados com silagem de milho e concentrado na proporção 58:42 da ração. A maior conversão alimentar obtida neste trabalho deve-se, possivelmente, à idade inicial dos animais (sete meses) e ao grupo racial (Santa Inês). Além disso, foram alimentados com feno de baixo valor nutritivo, suplementado com concentrado contendo dejeto de suínos "biju", enquanto Carvalho et al. (1999) buscaram resposta animal máxima para as diferentes categorias da raça Texel.

As repostas para conversão alimentar se assemelharam às obtidas por Rodrigues et al. (1996a), ao trabalharem com animais com quatro meses de idade e inclusão de $30 \%$ de dejetos de suínos nas formas de "biju" e DPS na ração, resultando em conversão alimentar de 6,15 gMS/g de ganho de peso. A utilização de animais com idade inferior por Rodrigues et al. (1996a) poderia ter propiciado respostas superiores às do atual estudo, no entanto, a não-verificação destas respostas pode estar relacionada ao elevado nível de inclusão de dejeto de suínos à ração concentrada (30\%), equivalente a $24 \%$ da ração total.

Verificou-se efeito significativo para blocos (peso dos animais) sobre a conversão alimentar $(\mathrm{P}<0,05)$, com os ovinos mais pesados $(30,1 \pm 1,6 \mathrm{~kg})$ apresentando conversão alimentar 7,2 e resposta inferior em relação aos animais com $21,4 \pm 3,3 ; 24,5 \pm 1,0$ e $25,7 \pm 2,0 \mathrm{~kg}$, com conversão alimentar média de $5,25 \pm 0,13 \mathrm{~kg}$ de alimento/kg ganho de peso. Explica-se esse comportamento pelo elevado peso inicial dos animais, com nítido efeito do peso inicial sobre a conversão alimentar no bloco dos animais mais pesados, que excediam o peso preconizado por Barros et al. (1997), que recomendam o confinamento de animais com peso vivo corporal inicial entre 15 e $20 \mathrm{~kg}$.

\section{Conclusões}

A inclusão de dejeto de suínos "biju" em até $12,6 \%$ das rações para ovinos terminados em confinamento resulta em desempenho satisfatório para ganho de peso diário e conversão alimentar, ficando a decisão pela utilização deste subproduto na dependência do custo relativo dos demais ingredientes, quando da formulação de rações a custo mínimo.

\section{Literatura Citada}

ANTHONY, W.E. Feeding value of cattle manure of cattle. Journal of Animal Science, v.30, n.2, p.274-277, 1970.

ARNDT, D.L.; DAY, D.L.; HATFIELD, E.E. Processing and handling of animal excreta for refeeding. Journal of Animal Science, v.44, n.4, p.521-531, 1977.

ASSOCIATION OF OFFICIAL ANALYTICAL CHEMISTS AOAC. Official methods of analysis. 15.ed. Washington, D.C., 1990. $1117 \mathrm{p}$.

BARROS, N.N.; SIMPLÍCIO. A.A.; FERNANDES, F.D. Terminação de borregos em confinamento no Nordeste do Brasil. Sobral: EMBRAPA/CNPC, 1997. 24p. (Circular Técnica, 12)

BRASIL. Instrução Normativa no 15, de 17 de julho de 2001. Proibe a importação de ruminantes, embriões e produtos derivados destas espécies, quando procedentes e/ou originários de países que registraram casos autóctones da encefalopatia espongiforme bovina e dá outras providências. Diário Oficial da República Federativa do Brasil, Brasília, 18 jul. 2001.

CAMPOS, J. Tabelas para cálculo de rações. 2.ed. Viçosa, MG: Universidade Federal de Viçosa, 1995. 64p.

CARVALHO, C.; PIRES, C.C.; PERES, J.R.R. et al. Desempenho de cordeiros machos inteiros, machos castrados e fêmeas, alimentados em confinamento. Ciência Rural, v.29, n.1, p.129-133, 1999. 
CASTRO, A.B. Desempenho de ovinos suplementados com diferentes níveis de dejeto de suínos e feno de leucena (Leucaena leucocephala (Lam.) De Wit.). Fortaleza: Universidade Federal do Ceará, 1999. 42p. Dissertação (Mestrado em Zootecnia) - Universidade Federal do Ceará, 1999.

FERREIRA, J.J.; MENEZES, A.C.; PIRES, J.A.A. Efeito do dejeto seco de suíno no desempenho de novilhos confinados. In: REUNIÃO ANUAL DA SOCIEDADE BRASILEIRA DE ZOOTECNIA, 34., 1997, Juiz de Fora. Anais... Juiz de Fora: Sociedade Brasileira de Zootecnia, 1997. p.306-310.

FONSECA, C.E.M.; VALADARES FILHO, S.C.; SILVA, J.F.C. et al. Utilização de dejeto de suínos in natura na alimentação de bovinos. Revista Brasileira de Zootecnia, v.26, n.1, p.164-170, 1997a.

FONSECA, C.E.M.; VALADARES FILHO, S.C.; SILVA, J.F.C. et al. Digestibilidade aparente de dietas contendo dejeto de suínos in natura. Revista Brasileira de Zootecnia, Viçosa, MG, v.26, n.1, p.171-178, 1997b.

KILL, J.L.; DONZELE, J.L.; VALERIO, S.R. Determinação do valor nutritivo dos dejetos de suínos utilizando suíno em fase de terminação. In: REUNIÃO ANUAL DA SOCIEDADE BRASILEIRA DE ZOOTECNIA, 33., 1996, Fortaleza. Anais... Fortaleza: Sociedade Brasileira de Zootecnia, 1996. p.154-156.

KILL, J.L.; DONZELE, J.L.; VALERIO, S.R. et al. Valor nutritivo e inclusão dos dejetos de suínos para suínos em terminação. Revista Brasileira de Zootecnia, v.27, n.6, p.1151-1159, 1998.

LASCANO, C.E.; BOREL, R.; QUEIROZ, R. et al. Recomendations on the methodology for mensuring consumption and in vivo digestibility. In: RUIZ, M.E.; RUIZ, S.E. (Eds.). Ruminant Nutrition Research: methodological guidelines. San Jose, C.R.: Interamerican Institute for Cooperation on Agriculture. Latin American Network for Animal Production Sistems Research, 1992. p173-182.

MARTINS, A.R.V. Utilização de dejetos de suínos em dietas de ovinos em sistema de confinamento. Lavras: Universidade Federal de Lavras, 1997. 51p. Dissertação (Mestrado em Zootecnia) - Universidade Federal de Lavras, 1997.

NATIONAL RESEARCH COUNCIL - NRC. Nutrient requirements of sheep. 6.ed. Washington, D.C.: National Academy Press, 1985. 99p.

OLIVEIRA, M.C.; DONZELE, J.L.; FERREIRA, A.S. et al. Valor nutritivo de dejetos de suínos para leitões em crescimento. In: REUNIÃO ANUAL DA SOCIEDADE BRASILEIRA DE ZOOTECNIA, 33., 1996, Fortaleza. Anais... Fortaleza: Sociedade Brasileira de Zootecnia, 1996. p.130-132.

OLIVEIRA, M.V.M.; PÉREZ, J.R.O.; ALVES, E.L. et al. Avaliação da composição de cortes comerciais, componentes corporais e órgãos internos de cordeiros confinados e alimentados com dejetos de suínos. Revista Brasileira de Zootecnia, v.31, n.3, p.1459-1468, 2002 (Suplemento).

OLIVEIRA, P.A.V. Manual de manejo e utilização dos dejetos de suínos. Concórdia: EMBRAPA/CNPSA, 1993. 188p. (Documentos, 27).
OLIVEIRA, P.A. Impacto ambiental causado pelos dejetos de suínos. In: SIMPÓSIO LATINO-AMERICANO DE NUTRIÇÃO DE SUÍNOS, 33., 1994, São Paulo. Anais... São Paulo: Colégio Brasileiro de Nutrição Animal, 1994. p.130-132.

PÉREZ, J.R.O.; MARTINS, A.R.V.; OLIVEIRA, M.V.M. et al. Composição química, consumo e digestibilidade de dois tipos de dejetos de suínos. In: REUNIÃO ANUAL DA SOCIEDADE BRASILEIRA DE ZOOTECNIA, 37., 2000, Viçosa. Anais... Viçosa: Sociedade Brasileira de Zootecnia, 2000. p.369.

RIBEIRO, K.G.; GARCIA, R.; PEREIRA, O.G. et al. Consumo e digestibilidades aparentes total e parcial, de nutrientes, em bovinos recebendo rações contendo feno de capim-tifton 85 de diferentes idades de rebrota. Revista Brasileira de Zootecnia, v.30, n.2, p.573-580, 2001

RODRIGUES, A.; PÉREZ, J.R.O.; OLIVEIRA, M.V.M. Desempenho de cordeiros Santa Inês e Bergamácia, terminados em confinamento, usando dejetos de suínos como parte da dieta. In: REUNIÃO ANUAL DA SOCIEDADE BRASILEIRA DE ZOOTECNIA, 33., 1996. Fortaleza. Anais... Fortaleza: Sociedade Brasileira de Zootecnia, 1996a. p.208-210.

RODRIGUES, A.; PÉREZ, J.R.O.; BARBOSA, C.M.P. Composição química, consumo e digestibilidade de dois tipos de dejetos de suínos obtidos de formas diferentes. In: REUNIÃO ANUAL DA SOCIEDADE BRASILEIRA DE ZOOTECNIA, 33., 1996, Fortaleza. Anais... Fortaleza: Sociedade Brasileira de Zootecnia, 1996b. p.139-141.

ROPPA, L. Situação atual e tendências da suinocultura mundial. In: SEMINÁRIO INTERNACIONAL DE SUINOCULTURA, 4., 1999, São Paulo. Anais... Piracicaba: Escola Superior de Agricultura Luiz de Queiroz, 1999. p.108-121.

RUIZ, M.E. Methodology for Production Trials: growth and fattening. In: RUIZ, M.E.; RUIZ, S.E. (Eds.). Ruminant Nutrition Research: methodological guidelines. San Jose, C.R.: Interamerican Institute for Cooperation on Agriculture. Latin American Network for Animal Production Sistems Research, 1992. p.281-297.

STATISTICAL ANALYSES SYSTEM - SAS. User's guide. Cary: 2000.

SILVA, D.J.; QUEIROZ, A.C. Análise de alimentos: métodos químicos e biológicos. 3.ed. Viçosa: Universidade Federal de Viçosa, 2002. 235p.

TILLEY, J.M.A.; TERRY, R.A. A two-stage technique for the in vitro digestion of forage crops. Journal British Grassland Society, v.18, n.2, p.104-111, 1963.

TINNIMIT, P.; YU, Y.; McGUFFEY, K. et al. Dried animal waste as protein supplement for sheep. Journal of Animal Science, v.35, n.2, p.431-435, 1972 . 